\title{
Local Variation of Toxicity and Toxin Composition in a Xanthid Crab Atergatis floridus
}

\author{
Tamao Noguchi, Kinue Koyama, Atsushi Uzu, \\ and Kanehisa HaSHIMOTO*
}

(Accepted March 30, 1983)

\begin{abstract}
Eighty-two specimens of a xanthid crab, "subesube-manjugani" Atergatis floridus were collected from four places on Ishigaki and Hachijo Islands, Miura Peninsula, etc., along with the Pescadores (Taiwan) in 1981 and 1982 . Toxicity assays of paralytic shellfish poison showed that all of them were toxic and their toxicity scores widely differed depending upon the places of collection. Ishigaki specimens were most toxic, and the maximum toxicity of $9,000 \mathrm{MU} / \mathrm{g}$ recorded. Miura specimens were moderately toxic all the year round. Incidentally, the fertilized eggs from seven female specimens were also found to be toxic.

Electrophoretic analyses showed that the main toxins of the Ishigaki specimens were neosaxitoxin and saxitoxin, whereas the Miura specimens lacked in neosaxitoxin.
\end{abstract}

As has already been reported ${ }^{1-4)}$, three xanthid crabs, "umore-ogigani" Zosimus aeneus, "subesube-manjugani" Atergatis floridus and "tsubuhiraashi-ogigani" Platypodia granulosa are toxic.

One of them, "subesube-manjugani" A. floridus widely inhabits the Ryukyu and Amami Islands. ") This species of crab inhabits also the Japan Proper and adjacent islands but its toxicity has not been screened satisfactorily, as far as these areas are concerned.

This time, specimens of $A$. floridus were collected from Miura Peninsula, and Shikine, Hachijo, and Ishigaki Islands, and examined for toxicity. Some specimens from the Pescadores Islands, Taiwan, were also examined. In addition, the Miura and Ishigaki specimens were analyzed for toxin composition and compared.

\section{Materials and Methods}

\section{Materials}

Specimens of "subesube-manjugani" Atergatis floridus were collected in April 1981 through July 1982 , by hand at an ebb-tide or by a gill net (Table 1). Most of them were immediately frozen or ice-cooled and transported to our laboratory. Some specimens were transported alive. All the specimens were kept frozen at $-20^{\circ} \mathrm{C}$ until used.

\section{Assay Method of Toxicity}

Appendages were torn off from each specimen, homogenized in a mortar and examined for toxicity by the standard assay method for paralytic shellfish poison. ${ }^{b)}$

\section{Purification and Analysis of Toxin}

The appendages and carapaces of several Miura or Ishigaki specimens were minced in a mortar. To the homogenate were added 3 volumes of $80 \%$ ethanol acidified to pH 2.0 with hydrochloric acid and homogenized with an Ultra-Turrax homogenizer. The homogenate was centrifuged at $5,000 \mathrm{rpm}$ for $10 \mathrm{~min}$. This operation was repeated two more times. The supernatants were combined, concentrated under reduced pressure, and defatted with chloroform. The aqueous solution was evaporated in vacuo to dryness. The residue was dissolved in water, and treated batchwise with activated charcoal (Wako). The toxin adsorbed was eluted with $1 \%$ acetic acid in $20 \%$ ethanol, and evaporated to dryness. The residue was dissolved in water, adjusted to pH 5-7, and chromatographed on a Bio-Gel P-2 (Bio-Rad Lab.) column $(6.5 \times 35 \mathrm{~cm})$. The column was washed with water and then the toxin was eluted with $0.15 \mathrm{~N}$ acetic acid. Toxic fractions were combined, and concentrated to dryness. The solid was dissolved in a small amount of water and applied to a column $(1.5 \times$ $10-28 \mathrm{~cm})$ of Amberlite CG-50 $\left(\mathrm{H}^{+}\right.$form, Rohm

* Laboratory of Marine Biochemistry, Faculty of Agriculture, University of Tokyo, Bunkyo, Tokyo 113 (野口玉雄・小山組江・宇津 敦・橋本周久：東京大学宸学部). 
\& Haas). The column was washed with water, and the toxin was eluted by a linear-gradient using $0-1.0 \mathrm{~N}$ acetic acid. Toxic fractions were combined and freeze-dried. The partially purified preparation was analyzed electrophoretically for toxin composition, as described below.

Electrophoresis was performed on $5 \times 18 \mathrm{~cm}$ cellulose acetate membranes (Chemetron) using $0.08 \mathrm{M}$ Tris- $\mathrm{HCl}$ buffer ( $\mathrm{pH} 8.7$ ), under a constant current of $0.8 \mathrm{~mA} / \mathrm{cm}$ width for $30 \mathrm{~min}$. The toxins were visualized as a yellow or blue fiuorescent spot under UV ( $365 \mathrm{~nm}$ ) after spraying the strip with $1 \%$ hydrogen peroxide and heating it at $110^{\circ} \mathrm{C}$ for $5 \mathrm{~min}$. Three purified paralytic shellfish poison (PSP) preparations, one consisting of saxitoxin (STX) and neosaxitoxin (neoSTX), another one of gonyautoxins 1-4 $\left(\mathrm{GTX}_{1-4}\right)$, and the last one of gonyautoxin 8 $\left(\mathrm{GTX}_{8}\right)$ and its epimer, were provided as reported previously ${ }^{3,6,7)}$ and used as reference standards.

\section{Results}

Toxicity of A. floridus specimens

As shown in Tables 1 and 2, all the specimens were found to be toxic. Rather remarkable individual and local variations of toxicity were observed. As a whole, Ishigaki specimens were highly toxic, the highest score being $9,000 \mathrm{MU} / \mathrm{g}$. Eight specimens among them showed toxicity scores of more than $1,000 \mathrm{MU} / \mathrm{g}$, while the rest 200-800 MU/g. Most specimens from other localities showed toxicity scores less than 100 $\mathrm{MU} / \mathrm{g}$.

Incidentally, seven female specimens with fertilized eggs were obtained from Ishigaki Island and Miura Peninsula. As seen in Table 3, all the egg samples were recognized to be toxic. The toxicity was roughly comparable to or less than that of the parental appendages. In one case, however, the toxicity score of the eggs was clearly

Table 1. Toxicity of A. floridus specimens collected

\begin{tabular}{|c|c|c|c|c|}
\hline \multirow{2}{*}{ Place of catch } & \multirow{2}{*}{$\begin{array}{l}\text { Date of } \\
\text { catch }\end{array}$} & \multicolumn{3}{|c|}{$\begin{array}{l}\text { No. of specimens tested } \\
\text { (No. of toxic specimens) }\end{array}$} \\
\hline & & Male & Female & Total \\
\hline \multirow{8}{*}{$\begin{array}{l}\text { Miura Pen., } \\
\text { Kanagawa }\end{array}$} & May 1981 & $1(1)$ & $1(1)$ & $2(2)$ \\
\hline & Jun. " & $5(5)$ & $4(4)$ & $9(9)$ \\
\hline & Jul. " " & $12(12)$ & $10(10)$ & $22(22)$ \\
\hline & Aug. " & $6(6)$ & $5(5)$ & $11(11)$ \\
\hline & Sep. " & $5(5)$ & $3(3)$ & $8(8)$ \\
\hline & Nov. " & & & $6(6)$ \\
\hline & Dec. " & & $1(1)$ & $1(1)$ \\
\hline & Jan. 1982 & $1(1)$ & & $1(1)$ \\
\hline Shikine Is., Tokyo & Jul. 1981 & $1(1)$ & & $1(1)$ \\
\hline \multirow[t]{2}{*}{ Hachijo Is., Tokyo } & Dec. 1981 & $1(1)$ & $1(1)$ & $2(2)$ \\
\hline & May 1982 & $1(1)$ & & $1(1)$ \\
\hline \multirow{3}{*}{ Ishigaki Is., Okinawa } & Apr. 1981 & $1(1)$ & $2(2)$ & $3(3)$ \\
\hline & Jun. " " & $2(2)$ & $1(1)$ & $3(3)$ \\
\hline & Jul. $\quad " r$ & $7(7)$ & $2(2)$ & $9(9)$ \\
\hline \multirow{2}{*}{ The Pescadores, Taiwan } & Jul. 1982 & $3(3)$ & & $3(3)$ \\
\hline & & $46(46)$ & $30(30)$ & $82(82)$ \\
\hline
\end{tabular}

Tahle 2. A. foridus specimens, as classified by toxicity levels

\begin{tabular}{lcccccr}
\hline & & \multicolumn{2}{c}{ Toxicity level (MU/g) } \\
Place of catch & $2-49$ & $50-99$ & $100-499$ & $500-999$ & 1000 & Total \\
\hline Miura Pen. & 20 & 24 & 16 & 0 & 0 & 60 \\
Shikine Is. & 0 & 1 & 0 & 0 & 0 & 1 \\
Hachijo Is. & 3 & 0 & 0 & 0 & 0 & 3 \\
Ishigaki Is. & 0 & 0 & 3 & 4 & 0 & 15 \\
Taiwan & 3 & 0 & 0 & 0 & 0 & 3 \\
\hline
\end{tabular}


Table 3. Toxicity scores of the eggs and appendages of several $A$. floridus specimens

\begin{tabular}{ccc}
\hline \multirow{2}{*}{ Place of catch } & \multicolumn{2}{c}{ Toxicity (MU/g) } \\
\cline { 2 - 3 } & Eggs & Appendages \\
\hline & 11 & 13 \\
Miura Pen. & 27 & 25 \\
& 30 & 150 \\
& 4 & 20 \\
& 40 & 15 \\
Ishigaki Is. & 30 & 100 \\
\hline
\end{tabular}

higher than that of the parent.

\section{Purification and Analysis of the Toxin}

The toxin was partially purified from the Miura specimens by chromatography on Bio-Gel P-2 and Amberlite CG-50 as described above.

In case of the Ishigaki specimens, the toxin $(19,000 \mathrm{MU})$ was for the most part adsorbed on a Bio-Gel P-2 column and eluted with $0.15 \mathrm{~N}$ acetic acid. This fraction (Fr. A) showed a total toxicity of $15,000 \mathrm{MU}$. In the Bio-Gel P-2 chromatography, some toxins equivalent to $1,100 \mathrm{MU}$ were not adsorbed. Only a portion of the toxins was adsorbed on Amberlite CG-50, and eluted as described above (Fr. B). The unadsorbed toxins were, however, adsorbed on a column $(1.0 \times 5.0 \mathrm{~cm})$ of Dowex WGR $\left(\mathrm{OH}^{-}\right.$form, Dow Chemical Co.). After washing the column with water, the toxins were eluted with $0.5 \mathrm{~N}$ and $1.0 \mathrm{~N}$ acetic acid, and lyophilized (Fr. C).

The results of electrophoretic analysis of those toxin preparation and fractions are shown in Fig. 1 schematically.

The toxic fraction from the Miura specimens showed a single blue spot, whose $R m$ value coincided well with that of STX, and the toxin was identified as STX. In connection with this, two additional vague spots, both fluorescing very weakly, appeared with mobilities similar to that of GTX.

On the other hand, the toxin of the Ishigaki specimens consisted of several components. As shown in Fig. 1, Fr. A showed two bands. Since they agreed with STX and neoSTX in Rm values and were toxic to mice, the fast $(\mathrm{Rm}=1)$ and slow $(\mathrm{Rm}=0.58)$ components were identified as STX and neoSTX, respectively. The STX to neoSTX ratio was $55: 45$ in term of toxicity. Fr. B was separated into four components by electrophoresis. Because of the similarity of this pattern to that of $\operatorname{GTX}_{6},{ }^{8}$ ) these four components were supposed to have been derived from $\mathrm{GTX}_{5}$.

On the other hand, Fr. C was separated into two components migrating toward the anode. Their relative mobilities did not coincide with those of $\mathrm{GTX}_{8}$ and its epimer. ${ }^{7}$ ) Due to scarcity of the sample available, further studies on these components were given up.

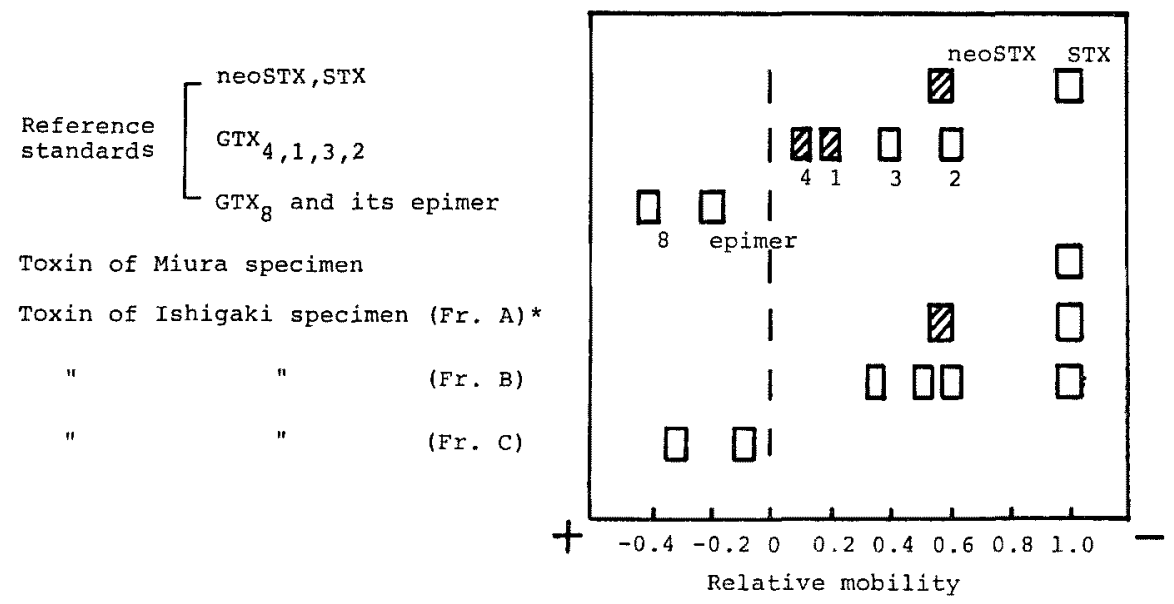

Fig. 1. Electrophoresis of the toxins of A. floridus specimens from Miura Peninsula and Ishigaki Island.

greenish yellow fluorescene; $\square$ blue fluorescence; * see the text. 


\section{Discussion}

As described above, the toxicity of $A$. floridus showed a wide local variation. It may be reasonable to assume that this variation is associated with environmental factors such as water temperature, food, the conditions of sea bottom, etc.

We reported before ${ }^{9)}$ that toxic crab species are endowed with much larger PSP resistibility than are nontoxic other crabs. We have not found any organism which can be the origin of PSP. ${ }^{10)}$ As described above, the eggs of toxic $A$. floridus females were also toxic. In addition, we observed recently that toxic crabs maintain a fairly high toxicity level for a long period when fed nontoxic diets.* Therefore, the possibility can not be excluded that the toxification is associated with some inherent factors in crabs. Further biochemical and ecological studies on toxic crabs may be essential to elucidate the toxification mechanism involved.

\section{Acknowledgements}

The authors are indebted to Director Dr. S. AragakI and Mr. M. Murakoshi, the Yaeyama Branch of the Okinawa Prefectural Fisheries Experimental Station, to Mr. K. SEZAKI, Enoshima Aquarium, and to Mr. K. HAYASHI, Yokosuka Municipal Museum, for their kind collaboration in collecting the crab specimens.

The work was supported in part by a grant from the Ministry of Agriculture, Forestry and Fisheries.

\section{References}

1) Y. Hashimoto, S. Konosu, A. Inoue, T. Saisho, and S. MrYAKe; Bull. Japan. Soc. Sci. Fish., 35, 83-87 (1969).

2) T. NoGuchi, S. Konosu, and Y. Hashimoto: Toxicon, 7, 325-326 (1969).

3) K. Koyama, T. Noguchi, Y. Ueda, and K. Hashimoto: Bull, Japan. Soc. Sci. Fish., 47, 965 (1981).

4) T. Yasumoto, Y. Oshima, and T. Konta: Bull. Japan. Soc. Sci. Fish., 47, 957-959 (1981).

5) Environmental Health Bureau, Ministry of Health and Welfare (ed.): Food Hygiene Examination Manual, Japan Food Hygiene Association, Tokyo, 1978, vol. 2, pp. 240-244.

6) Y. Ueda, T. NoguchI, K. Koxama, M. Kono, Y. ONoue, and K. Hashimoto: Bull. Japan. Soc. Sci. Fish., 48, 455-458 (1982).

7) $Y$. Onoue, T. Noguchi, J. Maruyama, K. Hashrmoto, and H. Seto: J. Agri. Food Chem., 31, 420-423 (1983).

8) S. Nisho, T. Noguchi, Y. Onove, J. Maruyama, K. Hashmoto, and H. SETo: Bull. Japan. Soc. Sci. Fish., 48, 959-965 (1982).

9) K. Koyama, T. Noguchl, A. Uzu, and K. Hashimoto: Bull. Japan. Soc. Sci. Fish., 49, 485489 (1983).

10) T. Saisho, T. Noguchi, K. Koyama, A. UzU, T. KikUtA, and K. Hashimoto: Bull. Japan. Soc. Sci. Fish., 49, 939947 (1983),

* T. Noguchi, K. Koyama, A. Uzu, and K. Hashimoto: The Abstracts of Oral Presentation at the Spring Meeting of Japan. Soc. Sci. Fïsh., p. 269 (1982). 